\title{
Effective aerosol optical depth from pyranometer measurements of surface solar radiation (global radiation) at Thessaloniki, Greece
}

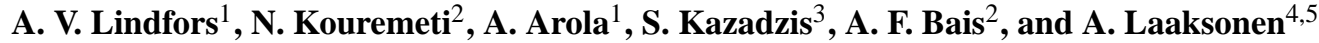 \\ ${ }^{1}$ Kuopio Unit, Finnish Meteorological Institute, Kuopio, Finland \\ ${ }^{2}$ Laboratory of Atmospheric Physics, Aristotle University of Thessaloniki, Thessaloniki, Greece \\ ${ }^{3}$ National Observatory of Athens, Athens, Greece \\ ${ }^{4}$ Climate Change Unit, Finnish Meteorological Institute, Helsinki, Finland \\ ${ }^{5}$ Department of Applied Physics, University of Eastern Finland, Kuopio, Finland
}

Correspondence to: A. V. Lindfors (anders.lindfors@fmi.fi)

Received: 13 August 2012 - Published in Atmos. Chem. Phys. Discuss.: 20 December 2012

Revised: 11 March 2013 - Accepted: 20 March 2013 - Published: 9 April 2013

\begin{abstract}
Pyranometer measurements of the solar surface radiation (SSR) are available at many locations worldwide, often as long time series covering several decades into the past. These data constitute a potential source of information on the atmospheric aerosol load. Here, we present a method for estimating the aerosol optical depth (AOD) using pyranometer measurements of the SSR together with total water vapor column information. The method, which is based on radiative transfer simulations, was developed and tested using recent data from Thessaloniki, Greece. The effective AOD calculated using this method was found to agree well with colocated AERONET measurements, exhibiting a correlation coefficient of 0.9 with $2 / 3$ of the data found within $\pm 20 \%$ or \pm 0.05 of the AERONET AOD. This is similar to the performance of current satellite aerosol methods. Differences in the AOD as compared to AERONET can be explained by variations in the aerosol properties of the atmosphere that are not accounted for in the idealized settings used in the radiative transfer simulations, such as variations in the single scattering albedo and Ångström exponent. Furthermore, the method is sensitive to calibration offsets between the radiative transfer simulations and the pyranometer SSR. The method provides an opportunity of extending our knowledge of the atmospheric aerosol load to locations and times not covered by dedicated aerosol measurements.
\end{abstract}

\section{Introduction}

In order to achieve a better understanding of the radiative properties of aerosols and their influence on earth's climate, major measurement activities using both satellites and ground-based instruments have been initiated over the last 10-20 yr (e.g., Holben et al., 1998; McArthur et al., 2003; Remer et al., 2005; Kahn et al., 2010). For the pre-1990 period, however, aerosol information is harder to find, and current aerosol-climate models are, for example, relying on emission-based estimates of the past aerosol load for most of the 20th century.

Meteorological surface observations constitute a potential source of information on the past atmospheric aerosol load. Wang et al. (2009), for example, used visibility observations as a proxy for studying the evolution of the aerosol optical depth (AOD) over land since 1973, while Ohvril et al. (2009) used measurements of the direct solar radiation at various stations in Russia, Ukraine, and Estonia for estimating the atmospheric transparency, a quantity that can be translated into AOD. The oldest data included in the study by Ohvril et al. (2009) date back to 1906. Unfortunately, such data exist only for few selected stations.

Pyranometer measurements of surface solar radiation (SSR, also called global radiation; see, e.g., WMO, 1982) are, on the other hand, available on many locations worldwide and often cover a period of several decades as many stations were founded during the International Geophysical Year 1957-1958. These historical data records have already 
provided a suite of interesting results on the decadal variations of the SSR and their connection to variations in aerosols and clouds (Wild, 2009, and references therein). These studies are mostly based on monthly SSR data which means that separating the effects of aerosols and clouds is not straightforward. Indirect methods have been applied, however, providing plausible evidence of the contribution of anthropogenic aerosol emissions to global dimming and brightening trends over the past decades (e.g., Stanhill and Cohen, 2001; Norris and Wild, 2009).

As indicated in previous work, more detailed aerosol information is available in SSR measurements taken under cloudless conditions. Ruckstuhl et al. (2008), for example, examined AOD trends and found corresponding changes in the cloud free SSR since 1980 at selected stations in Switzerland and Germany. Arola et al. (2007), on the other hand, evaluated the radiative effects of a plume of forest fire aerosols and found a reduction of $15 \%$ in the noontime SSR at Jokioinen in southern Finland. Moreover, Kudo et al. (2011) recently presented a method for estimating both AOD and single scattering albedo from a combination of pyranometer and pyrheliometer measurements of the diffuse and the direct radiation components. These studies imply that pyranometer data of SSR could perhaps be used for inferring the atmospheric aerosol load, providing a possibility to extend the existing aerosol record several decades into the past. The question is how accurately that can be done.

The aim of the present paper is to evaluate the potential of pyranometer measurements of SSR for quantifying the atmospheric aerosol load. In order to do this, we use recent data from Thessaloniki, Greece, where SSR measurements of high temporal resolution are available. These data are suitable for developing our method, and for testing our results against co-located Aerosol Robotic Network (AERONET) measurements of atmospheric aerosol properties.

\section{Data and location}

Thessaloniki is the second largest city in Greece, with a population of approximately 1 million inhabitants. It is situated in the northern part of the country on the northern shore of the Aegean Sea. Aerosol emission sources affecting Thessaloniki are both anthropogenic and natural. Local anthropogenic sources include domestic heating, traffic and industry, and the city is also influenced by transport of pollutants from Central and Eastern Europe and the Saharan desert (Samara and Voutsa, 2005; Kallos et al., 2007). Spectral measurements of the AOD show a seasonal variability with a maximum in summer and minimum in winter (Kazadzis et al., 2007). Thessaloniki experiences on average $10.0 \mathrm{~h}$ of daily sunshine in July, whereas in January the daily average sunshine is $2.9 \mathrm{~h}$ (Matzarakis and Katsoulis, 2006).

\subsection{Pyranometer SSR}

The SSR (surface solar radiation) is monitored at Thessaloniki since January 1993 with a CM21 pyranometer manufactured by Kipp and Zonen. The instrument is located on the roof of the Physics Department at the Aristotle University of Thessaloniki $\left(40^{\circ} 38^{\prime} \mathrm{N}, 22^{\circ} 57^{\prime} \mathrm{E}\right)$, ca. $60 \mathrm{~m}$ above sea level. In the morning, nearby buildings block the direct component of the solar irradiance for solar zenith angles (SZAs) larger than $75-80^{\circ}$, depending on season. The horizon is unobstructed for all azimuth angles except between $35^{\circ}$ and $120^{\circ}$.

The data are sampled every $1-2 \mathrm{~s}$ and every minute the average and standard deviation of the samples are recorded. The stability of the CM21 pyranometer was verified by two consecutive re-calibrations in 2005 and 2011, at the Deutscher Wetterdienst, Meteorologisches Observatorium Lindenberg, which proved that the sensitivity of the instrument has remained within $0.1 \%$ during $19 \mathrm{yr}$ of operation.

\subsection{AERONET}

AERONET is a network of Cimel sun photometers (Holben et al., 1998). Direct sun measurements in various channels (wavelengths) provide the AOD and the water vapor column. When also sky radiance measurements are included, more detailed aerosol properties such as single scattering albedo (SSA) and asymmetry parameter (gg) can be retrieved (Dubovik et al., 2000). The SSA is a measure of aerosol absorption (defined as the ratio of scattering efficiency to total extinction efficiency), and gg is a measure of the scattering phase function and depends on the size distribution of the aerosol particles. The Ångström exponent (AE), which describes the wavelength dependence of the AOD, is another parameter provided by AERONET related to the size distribution.

In this paper, we use Level 2.0 AERONET data for Thessaloniki, where the Cimel sun photometer is located at the roof of the Physics Department in the close vicinity of the pyranometer discussed above. We use the AERONET AOD at $500 \mathrm{~nm}\left(\mathrm{AOD}_{500}\right)$ as a reference when testing our method for estimating AOD from pyranometer measurements of SSR. Moreover, we utilize the climatological behavior of other aerosol properties such as SSA, AE and gg for evaluating the sensitivity of our method (Sect. 4.2).

Finally, we use the AERONET water vapor column both as input to our method and for testing the water vapor column provided by the ECMWF (see next subsection). Water vapor absorbs solar radiation in the infrared part of the spectrum and therefore needs to be accounted for when estimating the AOD from pyranometer measurements of SSR. 


\subsection{ECMWF water vapor}

The European Centre for Medium-range Weather Forecasts (ECMWF) provides not only global weather forecasts, but also analysis and reanalysis fields of, for example, temperature and humidity. These fields are based on the vast amount of observational data that are fed into the ECMWF model, and they represent a good approximation of the state of the atmosphere for a specific time. An advantage of these data is that they extend many decades back in time, thus providing necessary ancillary data for estimating the AOD from longterm pyranometer SSR records.

In this study, we use daily total water vapor column from the ECMWF ERA-Interim reanalysis (Dee et al., 2011). A comparison of the daily water vapor column from ECMWF with the daily average of the AERONET-retrieved values at Thessaloniki yields a correlation coefficient of 0.97 , with a systematic underestimation by the ECMWF of $7 \%$, or just above $1 \mathrm{~kg} \mathrm{~m}^{-2}$.

\section{Method}

\subsection{Effective AOD}

For estimating the atmospheric aerosol load from pyranometer measurements of the SSR taken under cloudless conditions, we use a lookup table which is based on radiative transfer simulations performed with the libRadtran package (Mayer and Kylling, 2005). We simulated the SSR under various atmospheric conditions: by systematically varying the AOD, the total water vapor column, and the SZA, we produced a lookup table that gives the effective AOD as

$\mathrm{AOD}_{\text {eff }}=f(\mathrm{SSR}, \mathrm{SZA}, \mathrm{WV})$,

where SSR as measured by the pyranometer is corrected to the same Earth-Sun distance as used in the radiative transfer simulations, and WV is the total water vapor column.

Details of the set-up of our radiative transfer simulations are given in Table 1. For the surface albedo, we used a narrowband albedo based on Briegleb et al. (1986). Their formulation assumes a SZA-dependence in the albedo, with somewhat higher values for low sun. For a SZA of $60^{\circ}$, the chosen albedo takes a value of 0.04 for wavelengths $200-500 \mathrm{~nm}$, 0.10 for $500-700 \mathrm{~nm}$, and 0.25 for $700-4000 \mathrm{~nm}$. We do not include any yearly cycle or day to day variation in the albedo.

In regards to the aerosol set-up, we started from the rural background aerosol model as defined by Shettle (1989). They assume a mixture of water soluble and dust-like aerosols, with a bimodal log-normal size distribution with mode radii of $0.03 \mu \mathrm{m}$ and $0.5 \mu \mathrm{m}$ for the fine and coarse mode, respectively. The overwhelming majority (ca. 999/1000) of the aerosol particles reside in the fine mode. For this aerosol mixture, the SSA (single scattering albedo) at $500 \mathrm{~nm}$ is around 0.96 and the AE (Ångström exponent) is ca. 1.1. Because the aerosol model includes hygroscopic growth of the particles, both the SSA and the AE depend somewhat on humidity. Most of the aerosol reside within the lowermost $2 \mathrm{~km}$ of the atmosphere and the aerosol extinction decreases rapidly with height above $2 \mathrm{~km}$.

This basic aerosol set-up was then modified to meet our needs. We scaled the AOD according to our choice of AOD at $500 \mathrm{~nm}$. Thus the original wavelength dependence of the AOD, as defined by the background aerosol properties, is retained. It should be also noted that according to our radiative transfer calculations, the response of the SSR to variations in the AOD is strongest for wavelengths just below $500 \mathrm{~nm}$, close to the peak in the surface solar radiation spectrum. Thus $\mathrm{AOD}_{\text {eff }}$ is representative of the AOD at $500 \mathrm{~nm}$. We also scaled the SSA using our choice of SSA at $500 \mathrm{~nm}$ as the baseline to meet, again retaining wavelength-dependent features. For Thessaloniki, we used SSA $=0.92$ at $500 \mathrm{~nm}$, which is considered representative based on the Thessaloniki AERONET data used in this study. Finally, we set gg (the asymmetry parameter) to a wavelength-independent value of 0.68 .

The detailed aerosol properties of the radiative transfer model will never exactly match those of the real atmosphere. Most importantly, the SSA, AE and gg, will vary from time to time. Therefore, $\mathrm{AOD}_{\text {eff }}$ inferred through Eq. (1) is necessarily an effective optical depth, corresponding to the AOD that exerts the same effect on the SSR as the aerosol of the real atmosphere, given the exact radiative properties of the aerosol as set up in the radiative transfer model.

Other factors not fully accounted for in our radiative transfer calculations are variations in the total column ozone, for which we use a constant value of $325 \mathrm{DU}$ in agreement with Brewer data at Thessaloniki, and variations in the surface pressure that is set to $1013 \mathrm{hPa}$. A sensitivity analysis shows that setting the ozone column and the surface pressure to constant values is equivalent to an additional uncertainty of $\pm 0.5 \%$ in the pyranometer measurements.

\subsection{Cloud screening}

When clouds are present, their effect on the measured SSR tends to dominate over that of aerosols. Therefore, we need to find the pyranometer measurements corresponding to cloud free conditions, and use that subset for estimating the aerosol load of the atmosphere.

Clouds are detectable in the measured SSR since they cause a larger variability in the SSR than aerosols. In order to distinguish between cloudy and essentially cloud free conditions, we apply an updated version of the method of Gröbner et al. (2001). A similar method has been presented also by Dutton et al. (2004). The idea of our method is to compare the measured SSR with radiative transfer calculations for cloud free conditions, with a libRadtran set-up that resembles the one described above for producing the lookup table (Eq. 1). 
Table 1. Set-up of radiative transfer calculations.

\begin{tabular}{lll}
\hline Section & Choice & Reference or comments \\
\hline solver & sdisort, pseudo-spherical & Dahlback and Stamnes (1991) \\
atmosphere & AFGL US standard profile & Anderson et al. (1986) \\
spectral resolution & kato2 band parameterization & optimized version of Kato et al. (1999) \\
surface albedo & spectral, surface type urban & Briegleb et al. (1986), libRadtran's albedo library \\
aerosol properties & rural background & Shettle (1989), scaled as explained in text \\
wavelength range & $310-2600 \mathrm{~nm}$ & Kipp and Zonen CM21 manual \\
\hline
\end{tabular}

We apply four tests to reach a decision on the cloud conditions:

i. The measured SSR has to lie within the modeled cloud free SSR for extreme aerosol loads; clean and turbid SSR, calculated using an AOD at $500 \mathrm{~nm}$ of 0.05 and 0.75 , respectively, corresponding to the 5 th and 95 th percentile of the Thessaloniki AERONET data for the examined period. Here, we use a lower SSA $=0.85$ because the aim is to produce an upper bound for the attenuation caused by aerosols.

ii. The rate of change in the measured SSR with SZA has to be within the limits depicted by the modeled cloud free SSR, otherwise the atmospheric extinction is assumed to be contaminated by clouds.

iii. All measured SSR values within a time window $(\mathrm{d} t=$ $30 \mathrm{~min}$ ) should be within $5 \%$ of $\mathrm{SSR}_{\mathrm{adj}}$. Here, $\mathrm{SSR}_{\mathrm{adj}}$ is the modeled cloud free SSR adjusted to the level of the measurement using integrals over $\mathrm{d} t$.

iv. If at least $85 \%$ of the points in dt pass tests (i)-(iii), then the central point is flagged cloud free.

In this study, we have allowed a tolerance level of $\pm 10 \%$ for tests (i) and (ii) in order to compensate for differences between the modeled and measured SSR due to instrumental uncertainties in spectral and cosine response as well as for usage of average climatological input parameters to the model (constant total ozone column, SSA, gg). Test (ii) is examined by applying piecewise linear fits over SZA intervals of $1^{\circ}$ on both measured and modeled SSR. Test (iii) aims to distinguish whether ripples in the measured SSR are due to aerosols or cirrus clouds.

\section{Results}

\subsection{Performance of the method}

Using the lookup table (Eq. 1) together with cloud screened SSR data and water vapor column from either AERONET observations or the ECMWF ERA-Interim reanalysis, we calculated $\mathrm{AOD}_{\text {eff }}$, and compared these values with Level
2.0 AERONET AOD 500 , available for the period September 2005 to January 2008.

Figure 1 shows the measured SSR together with modeled clear-sky SSR with various aerosol loads for two example days. Firstly, the figure illustrates the idea of the cloud screening method: on 4 August 2007, the measured SSR is smooth up to somewhat before 12:00 UTC, indicating cloud free conditions. Thereafter, the measured SSR shows strong variations caused by clouds, and therefore no pyranometerbased $\mathrm{AOD}_{\text {eff }}$ are available for that period. As the cloud grows thick during the afternoon, with a strong reduction in the measured SSR, also the AERONET AOD 500 lacks data for the latter part of the day. Furthermore, there is a short time window close to solar noon, i.e., around 10:30 UTC, where no $\mathrm{AOD}_{\text {eff }}$ data are available. This illustrates the sensitivity of the cloud screening algorithm; the small ripples in the measured SSR have caused this situation to be classified as cloudy. Note that 18 September 2005 is classified as essentially cloud free throughout the day in spite of some ripples in the measured SSR.

The figure further illustrates both strengths and weaknesses of the pyranometer-based AOD. Both days show a fair agreement between $\mathrm{AOD}_{\text {eff }}$ and $\mathrm{AOD}_{500}$. During 18 September 2005, also the temporal evolution over the day is captured well, although the pyranometer-based $\mathrm{AOD}_{\text {eff }}$ underestimates the true $\mathrm{AOD}_{500}$ during the hours around solar noon. We believe this change in the performance of the method between 08:00 UTC and 12:00 UTC can be explained by changes in the atmospheric aerosol properties that are not accounted for by our method (see Sect. 4.2 for a general discussion on this subject). In the afternoon hours (after 13:00 UTC), there is occasional overestimation which appears to be caused by misclassification of the cloud conditions by the cloud screening method: just before 14:00 UTC, there is a small dip in the measured SSR and a corresponding peak in the $\mathrm{AOD}_{\text {eff, }}$ probably caused by a cloud. During 4 August 2007 (Fig. 1, lower panel), the agreement is good between 06:00 and 08:00 UTC, with some underestimation elsewhere.

In order to lessen the amount of cloud contamination, and also to better demonstrate what would be possible to do with more long-term, historical SSR data, we also present results using hourly values of SSR. We calculated hourly values from the minute SSR data and cloud flags, requiring that all 

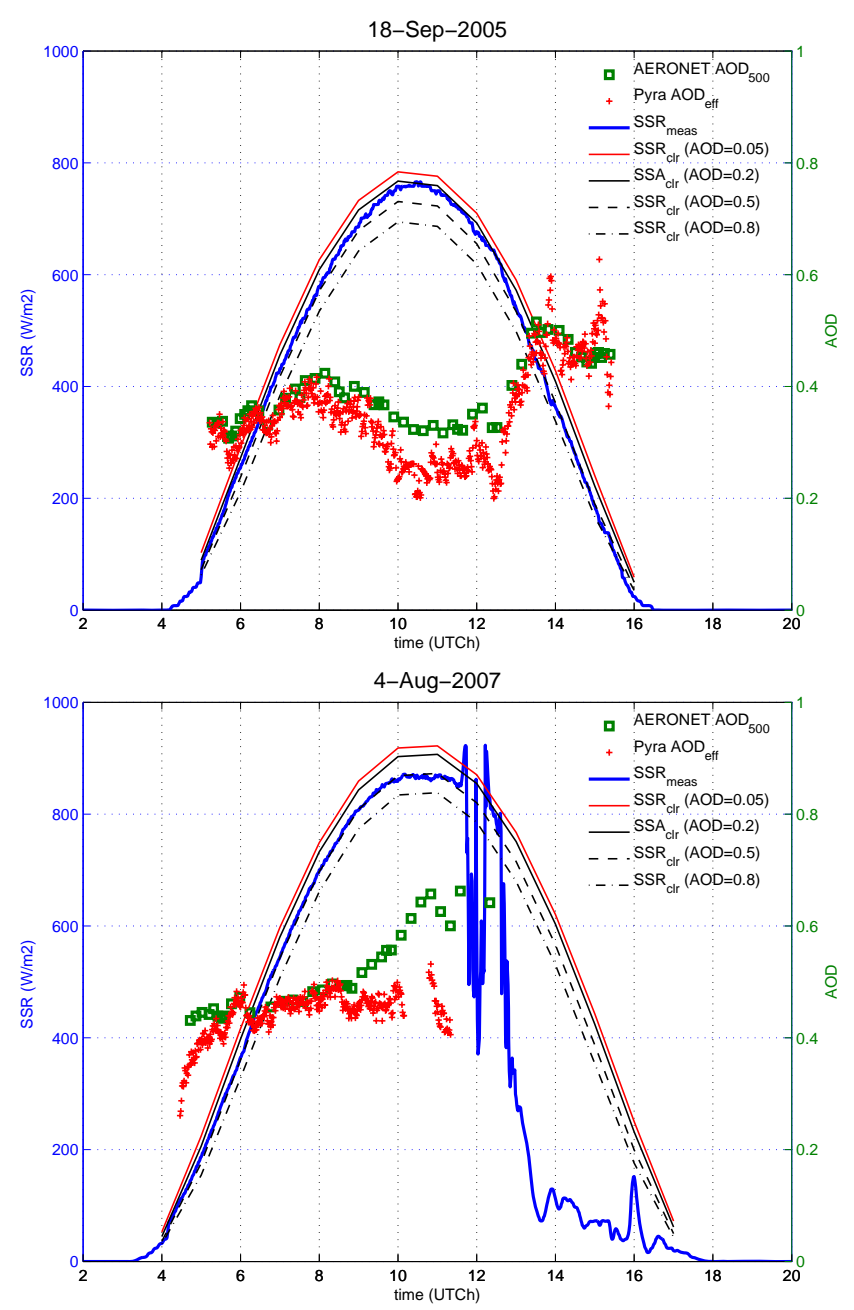

Fig. 1. Thessaloniki SSR (surface solar radiation) and AOD (aerosol optical depth) for selected days. The figure shows the effective AOD derived from SSR data (red crosses), the AERONET AOD at $500 \mathrm{~nm}$ (green open squares), the measured SSR (blue curve) and clear-sky simulated SSR for various aerosol loads (SSR curves for an AOD of 0.05, 0.2, 0.5, and 0.8).

minutes within the hour are flagged cloud free in order for the hourly cloud flag to be set to cloud free, hence introducing a more conservative cloud screening. Of course, this cloud screening would not be possible when working with longterm data records, available only as hourly values. For those, alternative cloud screening methods, utilizing ancillary data such as cloud fraction observations and/or sunshine duration could be used (e.g., Ruckstuhl and Philipona, 2008). Unfortunately, such data were not available for the present study.

Figure 2 and Table 2 present scatter plots and performance statistics of the pyranometer-based $\mathrm{AOD}_{\text {eff }}$ versus the AERONET $\mathrm{AOD}_{500}$. AOD $\mathrm{Aff}_{\text {ff }}$ was retrieved using either 1 min or $1 \mathrm{~h}$ values of the measured SSR and corresponding cloud flags, with either AERONET or ECMWF water vapor column input (Table 2). For the 1 min values of SSR, each AERONET AOD 500 was matched with a 10 min averaged $\mathrm{AOD}_{\text {eff. }}$. For the $1 \mathrm{~h}$ values, each hourly $\mathrm{AOD}_{\text {eff }}$ was matched with the AERONET AOD $_{500}$ averaged over the same hour. Finally, we also compared daily average AODs.

The overall agreement is good with a correlation coefficient of $0.88-0.91$. The pyranometer-based $\mathrm{AOD}_{\text {eff }}$ is systematically overestimating the $\mathrm{AOD}_{500}$ by 0.02 or ca. $10 \%$ when using AERONET water vapor. This overestimation is somewhat stronger when using ECMWF water vapor, which is expected because of the underestimation of the water vapor column by ECMWF (Sect. 2.3). With AERONET water vapor, the fraction of points within $\pm 20 \%$ or \pm 0.05 of the AERONET $\mathrm{AOD}_{500}\left(W_{ \pm 20 \%, \pm 0.05}\right)$ is $0.67-0.69$, staying above 0.60 also with ECMWF water vapor and hourly SSR data. This is a realistic scenario of what kind of data would be available when looking into the past decades, and we therefore concentrate on results produced using ECMWF water vapor and hourly SSR in the remaining part of the paper (Figs. 3 and 4).

The performance of our method can be compared to that of current state-of-the-science satellite aerosol algorithms. MISR (Multiangle Imaging SpectroRadiometer) typically performs slightly better than our method, with a $W_{ \pm 20 \%, \pm 0.05}$ of $0.70-0.75$, although for the specific location of Thessaloniki the number is 0.48 (Kahn et al., 2010). For MODIS (Moderate Imaging Spectrometer), using a somewhat different performance statistics, the fraction of data within the expected error envelope of $\pm(0.05+15 \%)$ is around 0.70 (Levy et al., 2010), whereas the equivalent of our method is around 0.80 .

Figure 3 shows the difference $\mathrm{AOD}_{\text {eff }}-\mathrm{AOD}_{500}$ and the ratio $\mathrm{AOD}_{\text {eff }} / \mathrm{AOD}_{500}$ as a function of $\mathrm{SZA}$ and AERONET $\mathrm{AOD}_{500}$. The difference (upper row) stays rather constant versus SZA. As long as a fair amount of data points are available the difference varies moderately with $\mathrm{AOD}_{500}$, the average ratio staying in the $0.00-0.05$ range for $\mathrm{AOD}_{500}<0.45$. For $\mathrm{AOD}_{500}>0.45$, where only few observations exist, there is more variation in this agreement because of data sparsity. The ratio (lower row) shows a clear systematic behavior versus AOD, with increasing relative overestimation and scatter as the AOD approaches zero. The ratio also increases with SZA, from ca. 1.10 at $35^{\circ}$ to 1.25 at $75^{\circ}$. As the spread of the difference (upper right panel) decreases somewhat when going toward small AODs, the large scatter in the ratio (lower right panel) at small AODs can be explained mainly by the fact that a small absolute error will cause a large deviation in the ratio when $\mathrm{AOD}_{500}$ is small. Considering that the pyranometer measures the incoming SSR over a broad wavelength band, and from the whole hemisphere above including both the direct beam and the diffuse radiation, it is understandable that it is difficult to reach a good relative agreement for small AODs.

Figure 4 shows a time series of daily averaged pyranometer-based $\mathrm{AOD}_{\text {eff }}$ and $\mathrm{AERONET} \mathrm{AOD}_{500}$ for 

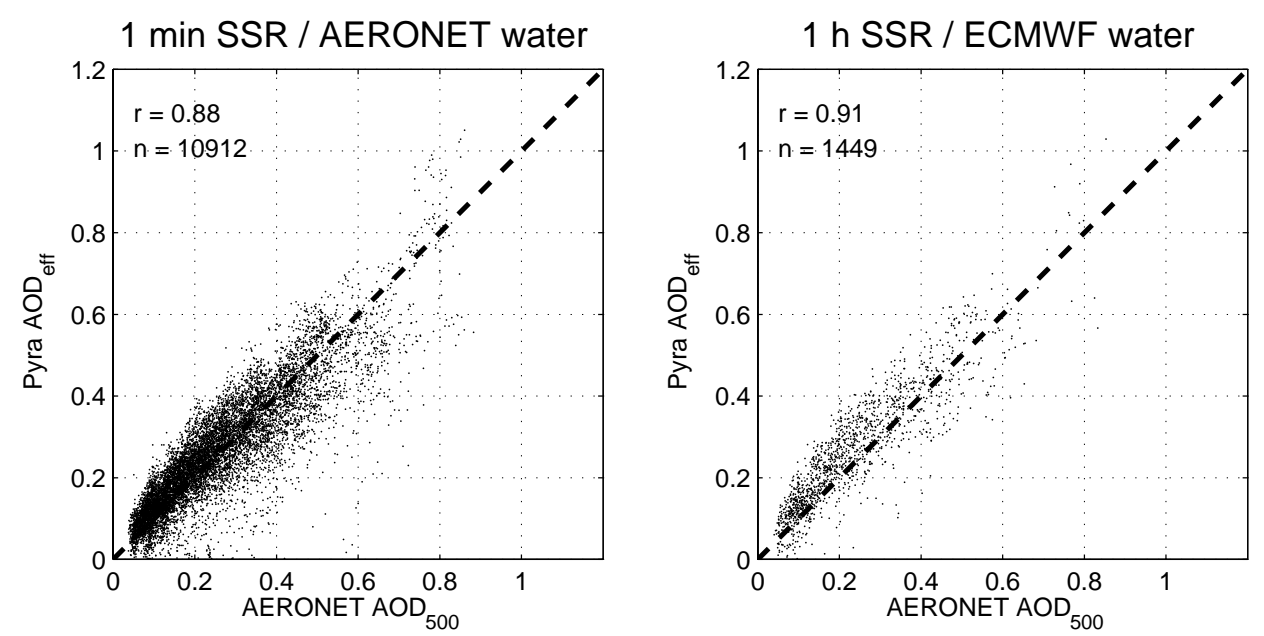

Fig. 2. Scatter plot of AERONET aerosol optical depth at $500 \mathrm{~nm}\left(\mathrm{AOD}_{500}\right)$ versus pyranometer-based effective aerosol optical depth $\left(\mathrm{AOD}_{\text {eff }}\right)$ using (left) one minute values of the surface solar radiation (SSR) and AERONET water vapor column, and (right) hourly values of the measured SSR and ECMWF water vapor column. $r$ is the correlation coefficient and $n$ is the number of data pairs.

Table 2. Performance of the method. SSR is surface solar radiation; $r$ is the correlation coefficient; $W_{ \pm 20 \%, \pm 0.05}$ is the fraction of data found within either $\pm 20 \%$ or \pm 0.05 of the reference value; md is the median difference; $\mathrm{mr}$ is the median ratio; std is the standard deviation of the ratio; and $n$ is the total number of data pairs.

\begin{tabular}{lllllllll}
\hline SSR data & water vapor input & time window & $r$ & $W_{ \pm 20 \%, \pm 0.05}$ & $\mathrm{md}$ & $\mathrm{mr}$ & std & $n$ \\
\hline $1 \mathrm{~min}$ & AERONET & $10 \mathrm{~min}$ & 0.88 & 0.67 & 0.02 & 1.08 & 0.07 & 10912 \\
$1 \mathrm{~h}$ & AERONET & $1 \mathrm{~h}$ & 0.91 & 0.69 & 0.02 & 1.11 & 0.06 & 1437 \\
$1 \mathrm{~h}$ & ECMWF & $1 \mathrm{~h}$ & 0.91 & 0.61 & 0.03 & 1.17 & 0.06 & 1449 \\
$1 \mathrm{~h}$ & ECMWF & $1 \mathrm{~d}$ & 0.89 & 0.63 & 0.03 & 1.11 & 0.07 & 329 \\
\hline
\end{tabular}

August 2006. The day-to-day variations in the aerosol load at Thessaloniki are captured well by our method, although both underestimation and overestimation can be seen, in particular during 1-3 and 17-21 August. Some of the deviations in the agreement can be explained by variations of the aerosol properties of the real atmosphere, which are not accounted for by our lookup table. This is further discussed in the next subsection. Thanks to fairly sunny weather, the data coverage of the pyranometer $\mathrm{AOD}_{\text {eff }}$ is good; only five days are missing during the whole month.

\subsection{Sensitivity of $\mathrm{AOD}_{\text {eff }}$}

Discrepancies between the pyranometer-based $\mathrm{AOD}_{\text {eff }}$ and AERONET $\mathrm{AOD}_{500}$ arise mainly because of two reasons: (i) differences in the aerosol properties of the real atmosphere and those used in the radiative transfer calculations (as discussed in Sect. 3.1); (ii) disagreement between the radiative transfer calculations and the pyranometer-measured SSR. Category (i) includes, for example, variations in the aerosol type, SSA and AE, while category (ii) includes the uncertainty of both the radiative transfer calculations and the SSR measurements, in addition to effects related to input to the radiative transfer model regarding parameters other than aerosols.

In order to examine the sensitivity of the estimated $\mathrm{AOD}_{\text {eff }}$ to various factors, we performed tests using the libRadtran radiative transfer model, producing perturbed SSR values corresponding to a calibration offset between the pyranometer SSR data and the radiative transfer model, and to deviations in aerosol optical properties from what was assumed when producing the lookup table (Eq. 1). The perturbed SSR values were then used to retrieve the $\mathrm{AOD}_{\text {eff }}$, thus indicating the sensitivity of $\mathrm{AOD}_{\text {eff }}$ to these factors. The results are shown in Table 3 for a SZA of $45^{\circ}$ and an $\mathrm{AOD}_{500}$ of 0.3. The ranges of the SSA, AE, and gg were chosen to correspond to the 5th and 95th percentile of these parameters according to the AERONET data of Thessaloniki.

Table 3 shows that calibration offsets between the radiative transfer simulations and the pyranometer measurements are important. A $3 \%$ offset causes a deviation of 0.14 in $\mathrm{AOD}_{\text {eff }}$ at a true AOD of 0.3 , thus corresponding to a relative error of almost $50 \%$. Of the aerosol properties, variations in the SSA have the largest effect on $\mathrm{AOD}_{\text {eff }}$, while also the $\mathrm{AE}$ and gg are of some importance. As these errors stay rather constant with AOD, the relative error easily grows large at 

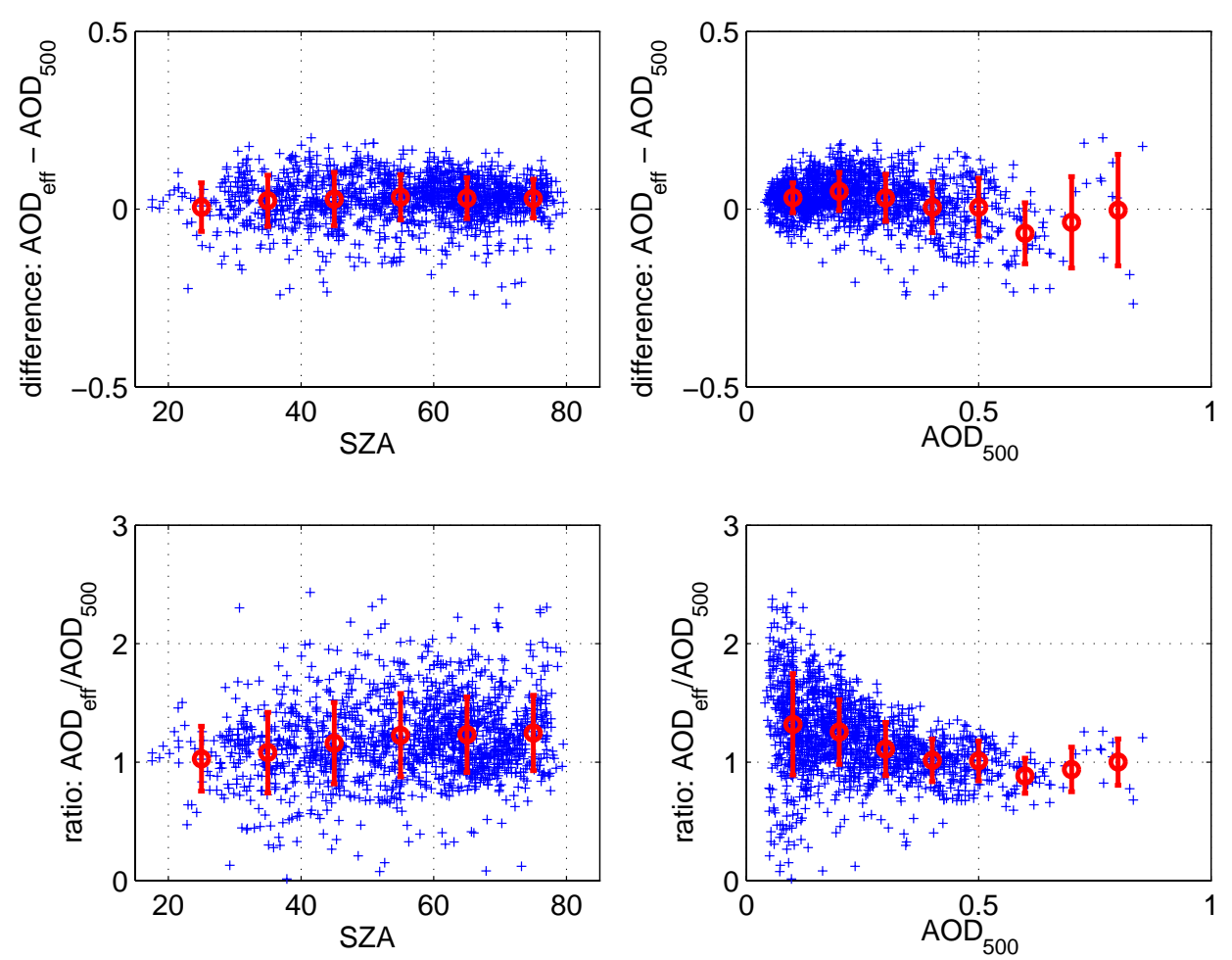

Fig. 3. Difference between and ratio of the pyranometer-based $A_{\text {OOff }}$ and AERONET $\mathrm{AOD}_{500}$ as a function of $\mathrm{AOD}_{500}$ and solar zenith angle (SZA). Group mean values and standard deviation are shown with red open circles and error bars.

Table 3. Sensitivity of the effective aerosol optical depth $\left(\mathrm{AOD}_{\mathrm{eff}}\right)$ to calibration offset and variations in aerosol optical properties. The sensitivity is shown as the deviation of $\mathrm{AOD}_{\text {eff }}$ from a true $\mathrm{AOD}_{500}=0.3$ at $\mathrm{SZA}=45^{\circ}$ as described more in detail in the text. SSA is the single scattering albedo, AE is the Ångström exponent and $g g$ is the asymmetry parameter.

\begin{tabular}{lrrr}
\hline factor & $\begin{array}{r}\text { assumed } \\
\text { in Eq. (1) }\end{array}$ & $\begin{array}{r}\text { perturbed } \\
\text { values }\end{array}$ & $\Delta \mathrm{AOD}_{\text {eff }}$ \\
\hline calibration offset & & $\pm 3 \%$ & $-0.14 / 0.14$ \\
$\mathrm{SSA}$ at $500 \mathrm{~nm}$ & 0.92 & $0.97 / 0.88$ & $-0.07 / 0.06$ \\
$\mathrm{AE}$ & 1.1 & $1.9 / 0.9$ & $-0.02 / 0.04$ \\
$\mathrm{gg}$ & 0.68 & $0.71 / 0.62$ & $-0.02 / 0.03$ \\
\hline
\end{tabular}

small AODs. This explains the large scatter in the relative agreement at small AOD 500 seen in Fig. 3 (lower right panel).

The AERONET Level 2.0 inversion products provide further insight into some features of Fig. 4. On 21 August 2006 , which is clearly overestimated by our method, the SSA at $440 \mathrm{~nm}(675 \mathrm{~nm})$ was around $0.91(0.94), \mathrm{gg}$ at $440 \mathrm{~nm}$ $(675 \mathrm{~nm})$ was $0.73(0.69)$, and the AE was 0.51 , which is well below the 5th percentile of the AE distribution (0.9). These properties, in particular the small wavelength dependence in the AOD (AE), indicate large atmospheric particles and influence of desert dust. On this day, the daily average

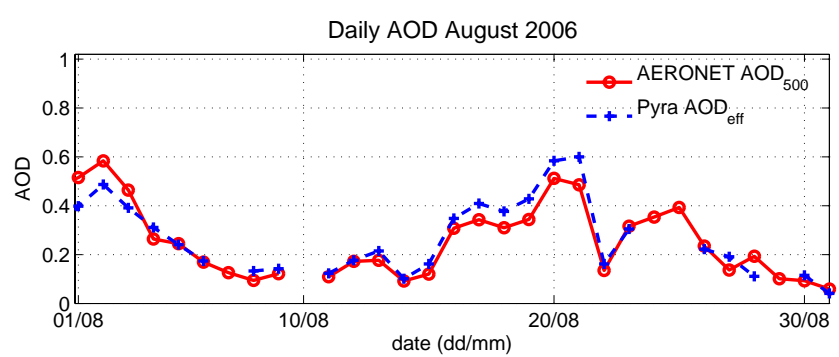

Fig. 4. Time series of daily averaged pyranometer-based $A D_{\text {eff }}$ and AERONET AOD 500 for August 2006.

$\mathrm{AOD}_{500}$ was 0.49 , while $\mathrm{AOD}_{\text {eff }}$ was 0.60 . Using the sensitivity analysis outlined above, we found that the small $\mathrm{AE}$ alone roughly explains the difference between $\mathrm{AOD}_{\text {eff }}$ and $\mathrm{AOD}_{500}$. The underestimation by our method seen during 12 August 2006, on the other hand, can to a large extent be explained by a fairly high SSA retrieved by AERONET (SSA at $440 \mathrm{~nm}$ around 0.95 ). 


\section{Conclusions}

We have developed a method for estimating the atmospheric aerosol load using pyranometer measurements of the SSR together with total water vapor column information. Compared to dedicated aerosol instruments such as sun photometers, pyranometers, measuring the incoming solar radiation (300$3000 \mathrm{~nm}$ ) from the whole hemisphere above, provide much less detailed information about the aerosol load. However, our results demonstrate that the proposed method is sensible, showing a fair agreement between the estimated effective aerosol optical depth $\left(\mathrm{AOD}_{\text {eff }}\right)$ and AERONET observations $\left(\mathrm{AOD}_{500}\right)$. In particular relative, temporal variations in the AOD are captured well, and the performance of the method is similar to current state-of-the-science satellite algorithms.

A sensitivity analysis (Sect. 4.2) indicates that deviations in the agreement between $\mathrm{AOD}_{\text {eff }}$ and $\mathrm{AOD}_{500}$ can be explained by variations in aerosol optical properties that are not accounted for by our method. For example, cases of strongly absorbing aerosols or large particles such as desert dust will cause a bias in the estimated $\mathrm{AOD}_{\text {eff }}$ as compared with $\mathrm{AOD}_{500}$. It should be noted, however, that this is an intrinsic feature of our method since $\mathrm{AOD}_{\text {eff }}$ is an effective quantity (see Sect. 3.1) corresponding to the AOD that matches the measured SSR, given the specific radiative properties of the aerosol as defined in the radiative transfer model. This means further that the pyranometer-based $\mathrm{AOD}_{\text {eff }}$ could be a useful quantity for studying the radiative effects of aerosols and their variation over time.

Possible improvements to the method could be achieved by better accounting for the expected aerosol type. If more detailed aerosol properties were available, these could be used to achieve more accurate estimates of the AOD. The recent development of the ECMWF model to include aerosols (Morcrette et al., 2009), for example, may provide useful information also for the past decades if aerosols were to be included in future reanalyses.

Pyranometers are available at many locations worldwide and old records of the SSR extend many decades back in time. These data provide a unique opportunity to extend our knowledge of the atmospheric aerosol load to times and locations not covered by dedicated aerosol measurements. This includes not only long time series, but also recent pyranometer data with high temporal resolution that could provide insight into the diurnal behavior of the AOD. It is worthwhile noting that long-term, historical pyranometer records will probably be available as hourly values at best, and that hourly values require a different cloud screening approach. Finally, as indicated by our sensitivity analysis, care needs to be taken regarding the calibration and homogeneity of the pyranometer records when applying this method.
Acknowledgements. AVL was funded by the Academy of Finland, decision 133259. The research has also been supported by the strategic funding of the University of Eastern Finland. We thank Jussi Kaurola for help with the ECMWF data.

Edited by: T. Petäjä

\section{References}

Anderson, G. P., Clough, S., Keizys, F., Chetwynd, J., and Shettle, E.: AFGL atmospheric constituent profiles (0-120 km), no. 954 in Environmental Research Papers, 1-43, United States, Air Force Geophysics Lab., Hanscom AFB, MA, 1986.

Arola, A., Lindfors, A., Natunen, A., and Lehtinen, K. E. J.: A case study on biomass burning aerosols: effects on aerosol optical properties and surface radiation levels, Atmos. Chem. Phys., 7, 4257-4266, doi:10.5194/acp-7-4257-2007, 2007.

Briegleb, B. P., Minnis, P., Ramanathan, V., and Harrison, E.: Comparison of Regional Clear-Sky Albedos Inferred from Satellite Observations and Model Computations, J. Clim. Appl. Meteorol., 25, 214-226, doi:10.1175/15200450(1986)025;0214:CORCSA 2 2.0.CO;2, 1986.

Dahlback, A. and Stamnes, K.: A new spherical model for computing the radiation field available for photolysis and heating at twilight, Planet. Space Sci., 39, 671-683, 1991.

Dee, D. P., Uppala, S. M., Simmons, A. J., Berrisford, P., Poli, P., Kobayashi, S., Andrae, U., Balmaseda, M. A., Balsamo, G., Bauer, P., Bechtold, P., Beljaars, A. C. M., van de Berg, L., Bidlot, J., Bormann, N., Delsol, C., Dragani, R., Fuentes, M., Geer, A. J., Haimberger, L., Healy, S. B., Hersbach, H., Holm, E. V., Isaksen, L., Kållberg, P., Köhler, M., Matricardi, M., McNally, A. P., Monge-Sanz, B. M., Morcrette, J.-J., Park, B.-K., Peubey, C., de Rosnay, P., Tavolato, C., Thepaut, J.-N., and Vitart, F.: The ERA-Interim reanalysis: configuration and performance of the data assimilation system, Q. J. Roy. Meteorol. Soc., 137, 553597, doi:10.1002/qj.828, 2011.

Dubovik, O., Smirnov, A., Holben, B., King, M., Kaufman, Y., Eck, T., and Slutsker, I.: Accuracy assessments of aerosol optical properties retrieved from Aerosol Robotic Network (AERONET) Sun and sky radiance measurements, J. Geophys. Res., 105, 9791-9806, doi:10.1029/2000JD900040, 2000.

Dutton, E. G., Farhadi, A., Stone, R. S., Long, C. N., and Nelson, D. W.: Long-term variations in the occurrence and effective solar transmission of clouds as determined from surface-based total irradiance observations, J. Geophys. Res.-Atmos., 109, 3204, doi:10.1029/2003JD003568, 2004.

Gröbner, J., Kouremeti, N., and Rembges, D.: A systematic comparison of solar UV radiation spectra with radiative transfer calculations, in: Proceedings of the 8th European Symposium on Physico-Chemical Behaviour of Air Pollutants, Torine, Italy, September 2001, 2001.

Holben, B., Eck, T., Slutsker, I., Tanre, D., Buis, J., Setzer, A., Vermote, E., Reagan, J., Kaufman, Y., Nakajima, T., Lavenu, F., Jankowiak, I., and Smirnov, A.: AERONET - A federated instrument network and data archive for aerosol characterization, Remote Sens. Environ., 66, 1-16, doi:10.1016/S00344257(98)00031-5, 1998.

Kahn, R. A., Gaitley, B. J., Garay, M. J., Diner, D. J., Eck, T. F., Smirnov, A., and Holben, B. N.: Multiangle Imaging SpectroRa- 
diometer global aerosol product assessment by comparison with the Aerosol Robotic Network, J. Geophys. Res.-Atmos., 115, D23209, doi:10.1029/2010JD014601, 2010.

Kallos, G., Astitha, M., Katsafados, P., and Spyrou, C.: Long-range transport of anthropogenically and naturally produced particulate matter in the Mediterranean and North Atlantic: Current state of knowledge, J. Appl. Meteorol. Climatol., 46, 1230-1251, doi:10.1175/JAM2530.1, 2007.

Kato, S., Ackerman, T. P., Mather, J. H., and Clothiaux, E. E.: The kdistribution method and correlated-k approximation for a shortwave radiative transfer model, J. Quant. Spectrosc. Radiat. Transfer, 62, 109-121, 1999.

Kazadzis, S., Bais, A., Amiridis, V., Balis, D., Meleti, C., Kouremeti, N., Zerefos, C. S., Rapsomanikis, S., Petrakakis, M., Kelesis, A., Tzoumaka, P., and Kelektsoglou, K.: Nine years of UV aerosol optical depth measurements at Thessaloniki, Greece, Atmos. Chem. Phys., 7, 2091-2101, doi:10.5194/acp-7-20912007, 2007.

Kudo, R., Uchiyama, A., Yamazaki, A., Sakami, T., and Ijima, O.: Decadal changes in aerosol optical thickness and single scattering albedo estimated from ground-based broadband radiometers: A case study in Japan, J. Geophys. Res., 116, D03207, doi:10.1029/2010JD014911, 2011.

Levy, R. C., Remer, L. A., Kleidman, R. G., Mattoo, S., Ichoku, C., Kahn, R., and Eck, T. F.: Global evaluation of the Collection 5 MODIS dark-target aerosol products over land, Atmos. Chem. Phys., 10, 10399-10420, doi:10.5194/acp-10-10399-2010, 2010.

Matzarakis, A. and Katsoulis, V.: Sunshine duration hours over the Greek region, Theor. Appl. Climatol., 83, 107-120, doi:10.1007/s00704-005-0158-8, 2006.

Mayer, B. and Kylling, A.: Technical note: The libRadtran software package for radiative transfer calculations - description and examples of use, Atmos. Chem. Phys., 5, 1855-1877, doi:10.5194/acp-5-1855-2005, 2005.

McArthur, L. J. B., Halliwell, D. H., Niebergall, O. J., O’Neill, N. T., Slusser, J. R., and Wehrli, C.: Field comparison of network Sun photometers, J. Geophys. Res., 108, 4596, doi:10.1029/2002JD002964, 2003.

Morcrette, J. J., Boucher, O., Jones, L., Salmond, D., Bechtold, P., Beljaars, A., Benedetti, A., Bonet, A., Kaiser, J. W., Razinger, M., Schulz, M., Serrar, S., Simmons, A. J., Sofiev, M., Suttie, M., Tompkins, A. M., and Untch, A.: Aerosol analysis and forecast in the European Centre for Medium-Range Weather Forecasts Integrated Forecast System: Forward modeling, J. Geophys. Res., 114, D06206, doi:10.1029/2008JD011235, 2009.
Norris, J. R. and Wild, M.: Trends in aerosol radiative effects over China and Japan inferred from observed cloud cover, solar dimming, and solar brightening, J. Geophys. Res.-Atmos., 114, D00D15, doi:10.1029/2008JD011378, 2009.

Ohvril, H., Teral, H., Neiman, L., Kannel, M., Uustare, M., Tee, M., Russak, V., Okulov, O., Joeveer, A., Kallis, A., Ohvril, T., Terez, E. I., Terez, G. A., Gushchin, G. K., Abakumova, G. M., Gorbarenko, E. V., Tsvetkov, A. V., and Laulainen, N.: Global dimming and brightening versus atmospheric column transparency, Europe, 1906-2007, J. Geophys. Res.-Atmos., 114, D00D12, doi:10.1029/2008JD010644, 2009.

Remer, L. A., Kaufman, Y. J., Tanre, D., Mattoo, S., Chu, D. A., Martins, J. V., Li, R., Ichoku, C., Levy, R. C., Kleidman, R. G., Eck, T. F., Vermote, E., and Holben, B. N.: The MODIS Aerosol Algorithm, Products, and Validation, J. Atmos. Sci., 62, 947973, doi:10.1175/JAS3385.1, 2005.

Ruckstuhl, C. and Philipona, R.: Detection of cloud-free skies based on sunshine duration and on the variation of global solar irradiance, Met. Z., 17, 181-186, doi:10.1127/0941-2948/2008/0271, 2008.

Ruckstuhl, C., Philipona, R., Behrens, K., Collaud Coen, M., Dürr, B., Heimo, A., Mätzler, C., Nyeki, S., Ohmura, A., Vuilleumier, L., Weller, M., Wehrli, C., and Zelenka, A.: Aerosol and cloud effects on solar brightening and the recent rapid warming, Geophys. Res. Lett., 35, L12708, doi:10.1029/2008GL034228, 2008.

Samara, C. and Voutsa, D.: Size distribution of airborne particulate matter and associated heavy metals in the roadside environment, Chemosphere, 59, 1197-1206, doi:10.1016/j.chemosphere.2004.11.061, 2005.

Shettle, E. P.: Models of aerosols, clouds and precipitation for atmospheric propagation studies, in: Atmospheric Propagation in the UV, Visible, IR and mm-region and Related System Aspects, no. 454 in AGARD Conf. Proc., 15-1-15-13, 1989.

Stanhill, G. and Cohen, S.: Global dimming: a review of the evidence for a widespread and significant reduction in global radiation with discussion of its probable causes and possible agricultural consequences, Agr. Forest Meteorol., 107, 255-278, doi:10.1016/S0168-1923(00)00241-0, 2001.

Wang, K., Dickinson, R. E., and Liang, S.: Clear Sky Visibility Has Decreased over Land Globally from 1973 to 2007, Science, 323, 1468-1470, doi:10.1126/science.1167549, 2009.

Wild, M.: Global dimming and brightening: A review, J. Geophys. Res.-Atmos., 114, D00D16, doi:10.1029/2008JD011470, 2009.

WMO: Commission for Instruments and Methods of Observation, Abridged Final Report of the Eighth Session, World Meteorological Organization (WMO), Geneva, 1982. 